Fertil Steril. 2013 December ; 100(6): . doi:10.1016/j.fertnstert.2013.08.008.

\title{
Ovulation-inducing drugs and ovarian cancer risk: results from an extended follow-up of a large US infertility cohort
}

\author{
Britton Trabert, Ph.D. ${ }^{a}$, Emmet J. Lamb, M.D. ${ }^{b}$, Bert Scoccia, M.D.c, Kamran S. Moghissi, \\ M.D. $^{d}$, Carolyn L. Westhoff, M.D. ${ }^{e}$, Shelley Niwa, M.A. ${ }^{f}$, and Louise A. Brinton, Ph.D. ${ }^{a}$ \\ aDivision of Cancer Epidemiology and Genetics, National Cancer Institute, Rockville, Maryland \\ ${ }^{b}$ Department of Obstetrics and Gynecology, Stanford University, Stanford, California 'Department \\ of Obstetrics and Gynecology, University of Illinois, Chicago, Illinois ${ }^{d}$ Department of Obstetrics \\ and Gynecology, Wayne State University, Detroit, Michigan eDepartment of Obstetrics and \\ Gynecology, Columbia University, New York, New York ${ }^{f}$ Westat, Inc., Rockville, Maryland
}

\begin{abstract}
Objective-To examine the relationship of ovulation-inducing drugs and ovarian cancer.

Design-Retrospective cohort study, with additional follow-up since initial report.

Setting-Five large reproductive endocrinology practices.

Patient(s) - In a retrospective cohort of 9,825 women evaluated for infertility at five clinical sites in the United States between 1965 and 1988 with follow-up through 2010, we examined the relationship of ovulation-inducing drugs and ovarian cancer $(\mathrm{n}=85)$.
\end{abstract}

Intervention(s)-None.

Main Outcome Measure(s)-Hazard rate ratios (RR) and 95\% confidence intervals (CI) for ovarian cancer.

Result(s)-Among women evaluated for infertility, there was no association of ovarian cancer risk with ever use of clomiphene citrate (CC) (adjusted RR 1.34, 95\% CI 0.86-2.07) or gonadotropins (RR 1.00, 95\% CI 0.48-2.08) and no evidence that any of several more detailed subgroups of usage were related to an increased risk with one exception: women who used CC and remained nulligravid did demonstrate much higher risks than those who successfully conceived compared with nonusers (respectively, RR 3.63, 95\% CI 1.36-9.72 vs. RR 0.88, 95\% CI $0.47-$ 1.63).

Conclusion(s)-Our overall results were reassuring and consistent with other studies. A reason for an association between CC use and ovarian cancer among persistently nulligravid women remains to be determined. Given the large and increasing number of women treated with ovulation-inducing drugs, the increased risk of ovarian cancer among the subset of women who remained nulligravid should be further monitored.

\footnotetext{
Copyright $@ 2013$ American Society for Reproductive Medicine, Published by Elsevier Inc.

Reprint requests: Britton Trabert, Ph.D., 9609 Medical Center Drive, Room 7-E228, MSC \#9774, Bethesda, Maryland 20892-9774 (britton.trabert@nih.gov). .

B.T. has nothing to disclose. E.J.L. has nothing to disclose. B.S. has nothing to disclose. K.S.M. has nothing to disclose. C.L.W. has nothing to disclose. S.N. has nothing to disclose. L.A.B. has nothing to disclose.
} 


\section{Keywords}

Ovarian cancer; risk; infertility; clomiphene citrate; gonadotropins

Nulliparity and certain causes of infertility (e.g., endometriosis) are factors associated with an increased risk of ovarian cancer (1). The use of fertility treatment has grown substantially in recent decades, with ovulation-inducing drugs widely used as independent therapies or during IVF cycles. An association between ovulation-inducing drugs and ovarian cancer risk is biologically plausible, given that the most commonly used medications, clomiphene citrate (CC) and gonadotropins, are effective at stimulating ovulation-one of the main factors implicated in the etiology of ovarian cancer. Clomiphene citrate induces ovulation indirectly, is considered a first line treatment for women with anovulatory infertility, and is also widely used for ovulatory women with unexplained infertility. Gonadotropins stimulate ovulation directly through follicular recruitment and induced folliculogenesis.

Clomiphene citrate and gonadotropins have both been used since the early 1960s. An increased risk of ovarian cancer with ovulation-inducing drug use was suggested in two early studies $(2,3)$, whereas recent cohort studies among infertile women suggest no association (4-10). Concerns, however, persist given reports of increased risk among certain subgroups of women, namely increased risk among women who remain nulligravid despite ovulation-inducing drug use (2,11-13), increased risk with extended follow-up (12), and increased risk of borderline ovarian tumors $(3,9,14,15)$. The inconsistent results may be due to methodological limitations of the studies. Specifically, many of the cohort studies were limited by short duration of follow-up, young age of cohort participants, low statistical power (typically fewer than 20 cases), and lack of information on other predictors of ovarian cancer risk. Whereas, case-control studies are limited by validity of self-reported infertility drug use and the ability to distinguish the possible effects of infertility drug use from the effects of infertility itself. Furthermore, most studies were not able to account for indications for drug use or causes of infertility, which could independently affect ovarian cancer risk.

We evaluated the association of ovulation-inducing drug use with long-term ovarian cancer risk in a large US cohort of women evaluated for primary or secondary infertility who have been followed through active and passive means for almost three decades. In a previous analysis of this cohort, with an average of 18 years of follow-up, we found no substantial associations between $\mathrm{CC}$ or gonadotropin exposures and ovarian cancer risk (6), but were limited in our assessment given the relatively young age of the women and limited numbers of ovarian cancers $(n=45)$. We therefore undertook a more recent follow-up to further elucidate relationships of ovulation-inducing drug exposures to long-term ovarian cancer risk.

\section{MATERIALS AND METHODS}

Study design and methodology have been described previously (16). Briefly, the study cohort was comprised of women who sought advice for infertility between 1965 and 1988 at any of five large reproductive endocrinology practices in Boston, Chicago, Detroit, Palo Alto, and New York City. A total of 12,193 women with either primary or secondary infertility met study eligibility criteria. Women evaluated for reversal of a tubal ligation were not eligible. Trained abstractors abstracted data from the original records regarding the infertility workup (all procedures and tests), medications prescribed, menstrual and reproductive histories, and other factors that might affect health. Information from the clinical workup was used to define causes of infertility, as previously described (17). This 
study was approved by institutional review boards at the National Cancer Institute and the participating institutions.

Initial cohort follow-up was pursued during 1998-2001; due to the young age of study participants a second follow-up attempt was initiated and completed in 2010. Follow-up procedures included searches for updates of vital status and change of address through the National Death Index and several publically available and proprietary databases (Social Security Administration Death Master File, US Postal Service National Change of Address, MaxCOA - a national change of address database, and LexisNexis). A short questionnaire, ascertaining cancer diagnoses and cancer risk factors that might have changed over time (e.g., reproductive and menopausal status), was mailed to located subjects who had not previously indicated that they wanted no further follow-up. Cancers were also identified by linkages to cancer registries in the 14 states in which the majority of women resided (Arizona, California, Connecticut, Florida, Illinois, Indiana, Massachusetts, Michigan, New Hampshire, New Jersey, New York, Ohio, Pennsylvania, and Texas). For the $12.4 \%$ of women who resided outside of these states, outcome information was dependent on completed questionnaires, with attempts to validate self-reports of cancers by requesting records from the women's treating physicians. Another Social Security Administration Death Master File search was completed at the end of the study to identify new deaths.

After excluding the 1,319 women who requested no additional follow-up, 8 who were enrolled twice and 1 who requested removal from the study, we were able to obtain information related to death, development of cancer, or date last known alive and free of cancer for 10,025 of the remaining 10,865 study subjects $(92.3 \%)$. Outcome information was available from completed questionnaires or cancer registry linkages through 2010 for 9,411 subjects, for 469 it was defined from earlier follow-up efforts, and for 145 women from information available 1 or more years after first infertility evaluation in their original clinic records. Additional analytic exclusions included: 1 woman with a missing birthdate, 6 less than 18 years of age at entry, 15 with missing information on a cancer diagnosis date, 111 with less than 1 year of follow-up, and 67 with a bilateral oophorectomy during the first year of follow-up. After these additional exclusions, the analytic cohort consisted of 9,825 women with at least one intact ovary.

Information regarding $\mathrm{CC}$ and gonadotropin exposure, ascertained through clinic records as described, included total cumulative dosage, number of treatment cycles, and age at first use. Race, gravidity and/or parity at study entry, causes of infertility, and body mass index (BMI in kilograms per meter squared) at study entry were also defined through clinic records. Other potential confounding factors were obtained through questionnaire data, supplemented, as appropriate, by information in clinic records. The 1998-2001 questionnaire obtained extensive information on menstrual and reproductive history, use of exogenous hormones, anthropometric factors, cigarette smoking, alcohol consumption, and screening for breast and ovarian diseases. The shorter 2010 questionnaire obtained updated information on reproductive behavior, body size, gynecologic operations, use of menopausal hormones, and mammographic screening history. Questionnaires were obtained from 6,582 women (67\% of the analysis subjects); 5,349 completed the 1998-2001 questionnaire and 4,772 , the 2010 questionnaire (3,538 completed both).

\section{Statistical Analysis}

Cox proportional hazards regression was used to estimate hazard rate ratios (RR) and $95 \%$ confidence intervals (CI) for ovarian cancer associated with use of ovulation-inducing medications with age as the time metric and ties handled by complete enumeration. Followup time began 1 year after the date of first infertility evaluation and continued through the earliest date of cancer occurrence, death, date last known alive and free of cancer, or, if vital 
status depended on cancer registry linkage, a variable ending date, depending on when each registry had complete information (range of 2008-2010). For women identified either through clinic records or a completed questionnaire as having a bilateral oophorectomy, we further truncated follow-up based on the date of surgery.

Categories of cumulative dose (1-900 and $>900 \mathrm{mg}$ for CC; $1-24$ and $>24$ ampules for gonadotropins) and number of cycles $(<6$ and $\succ 6)$ were selected based on prior analyses $(6$, 16 ) and to ensure an adequate number of cases in each group for analysis. Tests for linear trends across categories of cumulative dose and number of cycles were calculated using an ordinal variable. Likelihood ratio tests for interaction across levels of gravidity at entry and gravidity at follow-up were computed based on cross-product terms with CC or gonadotropins. The assumption of proportional hazards for each medication variable was tested using a likelihood ratio test of interaction with the time-scale (continuous) based on cross-product terms. $P$ values for all comparisons were two sided and alpha $<.05$ indicated statistical significance. The SAS statistical software, version 9.2 (SAS Institute) was used for all analyses.

\section{RESULTS}

The 9,825 women who made up the analytic cohort contributed 256,448 person-years, with mean follow-up of 17.6 years for ovarian cancer cases $(n=85)$ and 26.2 years for noncases. The mean age at first clinic visit of all women was 30.1 years and the study population was predominantly white.

A total of $38.1 \%$ of the women had been exposed to $\mathrm{CC}$ and $9.7 \%$ to gonadotropins. Users of CC were more likely than nonusers to have been evaluated in New York, Boston, or Chicago, be white, have ever been pregnant (at either entry or follow-up), be ever users of oral contraceptives (OC), and have been diagnosed with either endometriosis or anovulation (Table 1). Users of gonadotropins were more likely than nonusers to have been evaluated in New York City, Boston, or Chicago, be white, entered the cohort at an older age, have remained nulliparous at follow-up, and have been diagnosed with endometriosis, anovulation, or a cervical disorder.

Ovarian cancer risk in this study population was significantly reduced for women who had ever been pregnant at first clinic visit or at follow-up (Table 2). Ovarian cancer risk in this cohort was increased among women who were overweight (BMI $25-29.9 \mathrm{~kg} / \mathrm{m}^{2}$ ) at first clinic visit) compared with women who were normal/underweight $\left(\mathrm{BMI}<25 \mathrm{~kg} / \mathrm{m}^{2}\right)$. Other factors commonly associated with a reduced risk of ovarian cancer (e.g., OC use, late age at menarche) were not associated with a reduced risk of ovarian cancer in this cohort. Specific causes of infertility were not identified as being associated with a substantially increased or decreased ovarian cancer risk, compared with women in the cohort with other causes of infertility.

After adjustment for study site, calendar year, and gravidity status at first clinic visit (ever pregnant at first clinic visit vs. nulligravid at first clinic visit), ever use of CC was not significantly related to ovarian cancer risk (adjusted RR 1.34, 95\% CI 0.86-2.07) (Table 3). There were no convincing trends of risk with cumulative dose, number of cycles, or age at first use of CC; however, subjects who received 1-900 mg of CC were at increased ovarian cancer risk (RR 1.93, 95\% CI 1.11-3.33).

Risk appeared to increase slightly by years since first $\mathrm{CC}$ use. However, the trend was not statistically significant $(0-15$ years since first use of CC: RR 1.22 , 95\% CI $0.61-2.45$; $16-$ 
30 years: RR 1.40, 95\% CI 0.80-2.45; >30 years: RR 1.64, 95\% CI 0.54-4.98; $P$ trend $=$. $15)$.

Ever use of gonadotropins was not associated with ovarian cancer (RR 1.00, 95\% CI 0.482.08), and there was no further discrimination of risk according to cumulative dose, number of cycles, or age at first use (Table 3). Seven of the eight ovarian cancer cases who received gonadotropins also received CC (presumably as first line treatment), and the risk estimates for this group were similar to those receiving CC alone (RR 1.20, 95\% CI 0.54-2.68 for those receiving CC and gonadotropins compared with RR 1.36, 95\% CI 0.85-2.17 for those receiving $\mathrm{CC}$ alone).

Based on the likelihood ratio test of interaction, the association between CC and ovarian cancer was significantly modified by gravidity status at follow-up (ever pregnant at followup vs. nulligravid at follow-up) (Table 4). Whereas, there was no association of CC use among women who had ever been pregnant (RR 0.88 , 95\% CI 0.47-1.63), those who remained nulligravid at follow-up showed a significantly increased risk associated with ever use of CC (RR 3.63, 95\% CI 1.36-9.72, $P$ value for interaction $=.001)$; this increased risk was consistent across the other categories of CC usage (cumulative dose, number of cycles, or age at first use) evaluated (results not shown). Age at follow-up, gravidity status at first clinic visit, or the causes of infertility did not modify the CC-ovarian cancer association $(P$ value for interaction >.05). Because a small number of women received gonadotropins, it was not possible to carry out a similar assessment of effect modification by ovarian cancer risk factors for gonadotropin exposure.

We were able to obtain medical verification for 68 of 85 ovarian cancers (80\%) through cancer registry or medical records. When we restricted analyses to these validated cancers, we saw little change in risk estimates compared with those derived for the total number of participants (results not shown). Furthermore, when restricting analyses to the 75 invasive epithelial ovarian cancers, there was little change in the risk estimates compared with those derived from the entire analytic population (results not shown).

\section{DISCUSSION}

Within our large cohort of patients with well-documented information on infertility treatment, causes of infertility, and potential confounders, we were able to extend our previous follow-up (6) with an additional decade of follow-up to provide further insights regarding the relationship of ovulation-inducing drugs to long-term ovarian cancer risk. Similar to our previous follow-up, the results were generally reassuring, with ever use of CC or gonadotropins not associated with ovarian cancer risk. We found an unexpected increased risk of ovarian cancer among women who received 1-900 $\mathrm{mg}$ of CC, but higher cumulative dose $(>900 \mathrm{mg})$ was not associated with an increased risk nor was there a relationship between ovarian cancer risk and the number of cycles of CC. Our study does, however, suggest that CC treatment among the subgroup of women who remained nulligravid at follow-up was associated with an increased ovarian cancer risk.

Previous studies have provided somewhat conflicting results regarding the effects of ovulation-inducing drugs on ovarian cancer risk. In the early 1990s, a meta-analysis of 12 case-control studies reported an increased risk of ovarian cancer with self-reported infertility treatment (odds ratio [OR] 2.8, 95\% CI 1.3-6.1, based on 3 of the 12 studies that contributed data to the meta-analysis) with a substantially elevated risk among nulligravid women relative to fertile women (OR 27.0, 95\% CI 2.3-315.6) (2); however, this finding was criticized (18) because it was based on 12 exposed cases and 1 exposed control and because exposure ascertainment relied on self-reported infertility treatment. Furthermore, the 
comparison with fertile women makes it impossible to separate the effect of infertility from the effect of the infertility treatment. The meta-analysis was followed by a report from a USbased cohort of infertile women suggesting that ever use of $\mathrm{CC}$ was associated with an elevated, albeit statistically nonsignificant, risk of ovarian cancer (RR 2.3, 95\% CI 0.5-11.4, based on 9 ovarian cancers), with an even higher risk among women who had taken CC for 12 or more monthly cycles (RR 11.1, 95\% CI 1.5-82.3, based on 5 of 9 ovarian cancers) (3). However, many tumors (45\%) in this study were borderline and information on other predictors of ovarian cancer risk among cohort members was limited.

These early studies were followed by a number of cohort studies among populations of women seeking treatment for infertility and the results from these studies have been largely null $(4-10,19,20)$. The lack of a convincing association between ovulation-inducing drugs and ovarian cancer risk in the current study is consistent with the findings from these recent cohort studies. However, most of these cohorts accrued fewer than 20 ovarian cancer cases at the time of publication $(4,5,9,10,19,20)$, which limited the evaluation of ovulationinducing drugs. At present, the largest cohort evaluation of infertility treatment and ovarian cancer risk is from a study in Denmark (8) among 54,362 women diagnosed with infertility between 1963 and 1998. This study included 156 invasive ovarian cancer cases identified through linkage with the Danish Cancer Registry, and reported no evidence of increased ovarian cancer risk associated with CC (RR 1.14, 95\% CI 0.79-1.64), the most commonly used ovulation-inducing drug in the cohort (8). However, information on causes of infertility as well as cumulative dose of drug use or age at first use was either not available or largely missing in the registry data.

The increased risk of ovarian cancer associated with CC treatment among nulligravid women in the current study is consistent with findings from a meta-analysis and a pooledanalysis of case-control studies $(2,12)$ as well as a recent case-control study (13). In this latter study, the risk of ovarian cancer was increased (OR 3.13) among women who despite fertility drug treatment remained nulligravid (13). Our finding was based on 13 exposed cases and should be interpreted with caution. Furthermore, it was not replicated in the Danish cohort study evaluating the $\mathrm{CC}-$ ovarian cancer association by parity $(P$ interaction $=.56)(8)$. However, as demonstrated in the recent case-control study by Kurta and colleagues (13), the risk was elevated among women who were both nulliparous and nulligravid, whereas women who conceived with fertility drug usage but remained nulliparous were not at increased risk. Therefore stratification by gravidity, rather than parity, may be more important to identifying increased ovarian cancer risk among women who used ovulation-inducing drugs.

Strengths of our study included a large cohort of women from different clinical sites, extended follow-up, and available information on other predictors of ovarian cancer risk including specific causes of infertility and gravidity. Weaknesses of our study included loss to follow-up; however, there was no evidence that those untraced through our follow-up methods differed from those who were traced (16). Although the number of ovarian cancers accrued during follow-up was more than in most similar cohorts, the precision of subgroup analysis was limited and should be interpreted with caution. We were unable to evaluate in detail whether ovulation-inducing drug associations varied according to tumor characteristics, of importance given increasing recognition of the etiologic heterogeneity of ovarian cancer (21). Furthermore, data on various potential confounding factors were available but completeness was not ideal. Therefore residual confounding by these and other correlates of infertility cannot be ruled out.

Overall our findings were generally reassuring in not confirming a link between use of ovulation-inducing drugs and risk of subsequent ovarian cancer. In comparisons with other 
infertile women, there was no evidence that use of either CC or gonadotropins were associated with a substantial risk of ovarian cancer. However, our study does suggest that ovarian cancer risk is increased among women with resistant infertility (those who remained nulligravid), supporting the need for longer follow-up of existing cohorts and additional studies to evaluate long-term effects on ovarian cancer risk.

\section{Acknowledgments}

The authors expressed their appreciation to Kristen Keating, Kerry Grace Morrissey, and Usha Singh of Westat, Inc., for managing the field aspects of this follow-up study and to Jerome Mabie and Dave Ruggieri of IMS, Inc., for assistance with file formulation and data analysis. Cancer incidence data have been provided by the following cancer registries and/or state departments of health: Arizona Cancer Registry; California Department of Public Health; State of Connecticut Department of Public Health; Florida Cancer Data System; Illinois Department of Public Health, Illinois State Cancer Registry; Indiana State Department of Health; Massachusetts Cancer Registry, Massachusetts Department of Public Health; Michigan Cancer Surveillance Program of the Michigan Department of Community Health; New Hampshire Department of Health and Human Services; New Jersey Cancer Registry; New York State Health Department; Ohio Cancer Incidence Surveillance System, Ohio Department of Health; Bureau of Health Statistics \& Research, Pennsylvania Department of Health; Texas Cancer Registry, Texas Department of State Health Services. The authors assume full responsibility for the analyses, interpretations, and conclusions in this publication and endorsement by the state cancer registries is not intended nor should be inferred.

Supported by the intramural research program of the National Cancer Institute, National Institutes of Health.

\section{REFERENCES}

1. Brinton LA, Sahasrabuddhe VV, Scoccia B. Fertility drugs and the risk of breast and gynecologic cancers. Semin Reprod Med. 2012; 30:131-45. [PubMed: 22549713]

2. Whittemore AS, Harris R, Itnyre J. Characteristics relating to ovarian cancer risk: collaborative analysis of 12 US case-control studies. II. Invasive epithelial ovarian cancers in white women. Collaborative Ovarian Cancer Group. Am J Epidemiol. 1992; 136:1184-203. [PubMed: 1476141]

3. Rossing MA, Daling JR, Weiss NS, Moore DE, Self SG. Ovarian tumors in a cohort of infertile women. N Engl J Med. 1994; 331:771-6. [PubMed: 8065405]

4. Modan B, Ron E, Lerner-Geva L, Blumstein T, Menczer J, Rabinovici J, et al. Cancer incidence in a cohort of infertile women. Am J Epidemiol. 1998; 147:1038-42. [PubMed: 9620047]

5. Doyle P, Maconochie N, Beral V, Swerdlow AJ, Tan SL. Cancer incidence following treatment for infertility at a clinic in the UK. Hum Reprod. 2002; 17:2209-13. [PubMed: 12151460]

6. Brinton LA, Lamb EJ, Moghissi KS, Scoccia B, Althuis MD, Mabie JE, et al. Ovarian cancer risk after the use of ovulation-stimulating drugs. Obstet Gynecol. 2004; 103:1194-203. [PubMed: 15172852]

7. dos Santos Silva I, Wark PA, McCormack VA, Mayer D, Overton C, Little V, et al. Ovulationstimulation drugs and cancer risks: a long-term follow-up of a British cohort. Br J Cancer. 2009; 100:1824-31. [PubMed: 19436296]

8. Jensen A, Sharif H, Frederiksen K, Kjaer SK. Use of fertility drugs and risk of ovarian cancer: Danish Population Based Cohort Study. BMJ. 2009; 338:b249. [PubMed: 19196744]

9. Sanner K, Conner P, Bergfeldt K, Dickman P, Sundfeldt K, Bergh T, et al. Ovarian epithelial neoplasia after hormonal infertility treatment: long-term follow-up of a historical cohort in Sweden. Fertil Steril. 2009; 91:1152-8. [PubMed: 18371964]

10. Lerner-Geva L, Rabinovici J, Olmer L, Blumstein T, Mashiach S, Lunenfeld B. Are infertility treatments a potential risk factor for cancer development? Perspective of 30 years of follow-up. Gynecol Endocrinol. 2012; 28:809-14. [PubMed: 22475084]

11. Mosgaard BJ, Lidegaard O, Kjaer SK, Schou G, Andersen AN. Infertility, fertility drugs, and invasive ovarian cancer: a case-control study. Fertil Steril. 1997; 67:1005-12. [PubMed: 9176436]

12. Ness RB, Cramer DW, Goodman MT, Kjaer SK, Mallin K, Mosgaard BJ, et al. Infertility, fertility drugs, and ovarian cancer: a pooled analysis of case-control studies. Am J Epidemiol. 2002; 155:217-24. [PubMed: 11821246] 
13. Kurta ML, Moysich KB, Weissfeld JL, Youk AO, Bunker CH, Edwards RP, et al. Use of fertility drugs and risk of ovarian cancer: results from a U.S.-based case-control study. Cancer Epidemiol Biomarkers Prev. 2012; 21:1282-92. [PubMed: 22707710]

14. Shushan A, Paltiel O, Iscovich J, Elchalal U, Peretz T, Schenker JG. Human menopausal gonadotropin and the risk of epithelial ovarian cancer. Fertil Steril. 1996; 65:13-8. [PubMed: 8557128]

15. Mosgaard BJ, Lidegaard O, Kjaer SK, Schou G, Andersen AN. Ovarian stimulation and borderline ovarian tumors: a case-control study. Fertil Steril. 1998; 70:1049-55. [PubMed: 9848294]

16. Brinton LA, Westhoff CL, Scoccia B, Lamb EJ, Trabert B, Niwa S, et al. Fertility drugs and endometrial cancer risk: results from an extended follow-up of a large infertility cohort. Hum Reprod. Aug 13.2013 [Epub].

17. Brinton LA, Lamb EJ, Moghissi KS, Scoccia B, Althuis MD, Mabie JE, et al. Ovarian cancer risk associated with varying causes of infertility. Fertil Steril. 2004; 82:405-14. [PubMed: 15302291]

18. Cohen J, Forman R, Harlap S, Johannisson E, Lunenfeld B, de MJ, et al. IFFS expert group report on the Whittemore study related to the risk of ovarian cancer associated with the use of infertility agents. Hum Reprod. 1993; 8:996-9. [PubMed: 8408507]

19. Potashnik G, Lerner-Geva L, Genkin L, Chetrit A, Lunenfeld E, Porath A. Fertility drugs and the risk of breast and ovarian cancers: results of a long-term follow-up study. Fertil Steril. 1999; 71:853-9. [PubMed: 10231045]

20. Calderon-Margalit R, Friedlander Y, Yanetz R, Kleinhaus K, Perrin MC, Manor O, et al. Cancer risk after exposure to treatments for ovulation induction. Am J Epidemiol. 2009; 169:365-75. [PubMed: 19037008]

21. Yang HP, Trabert B, Murphy MA, Sherman ME, Sampson JN, Brinton LA, et al. Ovarian cancer risk factors by histologic subtypes in the NIH-AARP Diet and Health Study. Int J Cancer. 2012; 131:938-48. [PubMed: 21960414] 


\section{TABLE 1}

Comparison of demographic factors by exposure to ovulation-inducing drugs among women evaluated for infertility at five US clinics between 1965 and 1988.

\begin{tabular}{|c|c|c|c|c|c|c|c|c|}
\hline & \multicolumn{4}{|c|}{ Clomiphene citrate } & \multicolumn{4}{|c|}{ Gonadotropins } \\
\hline & \multicolumn{2}{|c|}{$\begin{array}{r}\text { Ever } \\
(\mathbf{n}=\mathbf{3 , 7 4 5})\end{array}$} & \multicolumn{2}{|c|}{$\begin{array}{r}\text { Never } \\
(n=6,080)\end{array}$} & \multicolumn{2}{|c|}{$\begin{array}{r}\text { Ever } \\
(\mathbf{n}=\mathbf{9 5 2})\end{array}$} & \multicolumn{2}{|c|}{$\begin{array}{r}\text { Never } \\
(\mathbf{n}=\mathbf{8}, \mathbf{8 7 3})\end{array}$} \\
\hline & $\mathbf{n}$ & $\%$ & $\mathbf{n}$ & $\%$ & $\mathbf{n}$ & $\%$ & $\mathbf{n}$ & $\%$ \\
\hline \multicolumn{9}{|l|}{ Study site } \\
\hline New York and Boston & 1,372 & 36.6 & 1,816 & 29.9 & 344 & 36.1 & 2,844 & 32.0 \\
\hline Chicago & 1,132 & 30.2 & 1,734 & 28.5 & 402 & 42.2 & 2,464 & 27.8 \\
\hline Detroit & 897 & 24.0 & 1,256 & 20.7 & 129 & 13.6 & 2,024 & 22.8 \\
\hline Palo Alto & 344 & 9.2 & 1,274 & 21.0 & 77 & 8.1 & 1,541 & 17.4 \\
\hline \multicolumn{9}{|l|}{ Race } \\
\hline White & 3,067 & 81.9 & 4,391 & 72.2 & 788 & 82.8 & 6,670 & 75.2 \\
\hline African American & 96 & 2.6 & 351 & 5.8 & 10 & 1.1 & 437 & 4.9 \\
\hline Other & 170 & 4.5 & 363 & 6.0 & 65 & 6.8 & 468 & 5.3 \\
\hline Unknown & 412 & 11.0 & 975 & 16.0 & 89 & 9.4 & 1,298 & 14.6 \\
\hline \multicolumn{9}{|l|}{ Calendar year at first clinic visit } \\
\hline$<1975$ & 830 & 22.2 & 1,703 & 28.0 & 235 & 24.7 & 2,298 & 25.9 \\
\hline 1975-1979 & 1,296 & 34.6 & 2,111 & 34.7 & 248 & 26.1 & 3,159 & 35.6 \\
\hline 1980-1984 & 1,210 & 32.3 & 1,708 & 28.1 & 303 & 31.8 & 2,615 & 29.5 \\
\hline 1985-1988 & 409 & 10.9 & 558 & 9.2 & 166 & 17.4 & 801 & 9.0 \\
\hline \multicolumn{9}{|l|}{ Age at first clinic visit (y) } \\
\hline$<25$ & 306 & 8.2 & 572 & 9.4 & 66 & 6.9 & 812 & 9.1 \\
\hline $25-29$ & 1,491 & 39.8 & 2,358 & 38.8 & 329 & 34.6 & 3,520 & 39.7 \\
\hline $30-34$ & 1,383 & 36.9 & 2,131 & 35.1 & 348 & 36.5 & 3,166 & 35.7 \\
\hline $35-39$ & 464 & 12.4 & 849 & 14.0 & 164 & 17.2 & 1,149 & 12.9 \\
\hline$\geq 40$ & 101 & 2.7 & 170 & 2.8 & 45 & 4.7 & 226 & 2.5 \\
\hline \multicolumn{9}{|l|}{ Reproductive status at first clinic visit } \\
\hline Nulligravid & 1,495 & 39.9 & 2,683 & 44.1 & 386 & 40.5 & 3,792 & 42.7 \\
\hline Ever pregnant at first clinic visit & 2,250 & 60.1 & 3,397 & 55.9 & 566 & 59.4 & 5,081 & 57.3 \\
\hline \multicolumn{9}{|l|}{ Reproductive status at follow-up } \\
\hline Nulligravid & 517 & 13.8 & 862 & 14.2 & 159 & 16.7 & 1,220 & 13.7 \\
\hline Ever pregnant & 2,741 & 73.2 & 4,229 & 69.6 & 672 & 70.5 & 6,298 & 71.0 \\
\hline Missing & 487 & 13.0 & 989 & 16.3 & 121 & 12.7 & 1,355 & 15.3 \\
\hline \multicolumn{9}{|l|}{ Age at first birth (y) } \\
\hline Nulliparous & 800 & 21.4 & 1,268 & 20.9 & 252 & 26.5 & 1,816 & 20.5 \\
\hline$<25$ & 340 & 9.1 & 709 & 11.7 & 46 & 4.8 & 1,003 & 11.3 \\
\hline $25-29$ & 638 & 17.0 & 953 & 15.7 & 145 & 15.2 & 1,446 & 16.3 \\
\hline$\geq 30$ & 1,127 & 30.1 & 1,375 & 22.6 & 322 & 33.8 & 2,180 & 24.6 \\
\hline Unknown & 840 & 22.4 & 1,775 & 29.2 & 187 & 19.6 & 2,428 & 27.4 \\
\hline \multicolumn{9}{|l|}{ Age at menarche $(y)$} \\
\hline$<12$ & 725 & 19.4 & 1,200 & 19.7 & 166 & 17.4 & 1,759 & 19.8 \\
\hline
\end{tabular}

Fertil Steril. Author manuscript; available in PMC 2014 December 01. 


\begin{tabular}{|c|c|c|c|c|c|c|c|c|}
\hline & \multicolumn{4}{|c|}{ Clomiphene citrate } & \multicolumn{4}{|c|}{ Gonadotropins } \\
\hline & \multicolumn{2}{|c|}{$\begin{array}{r}\text { Ever } \\
(\mathrm{n}=\mathbf{3 , 7 4 5})\end{array}$} & \multicolumn{2}{|c|}{$\begin{array}{r}\text { Never } \\
(\mathrm{n}=\mathbf{6 , 0 8 0})\end{array}$} & \multicolumn{2}{|c|}{$\begin{array}{r}\text { Ever } \\
(\mathbf{n}=\mathbf{9 5 2})\end{array}$} & \multicolumn{2}{|c|}{$\begin{array}{r}\text { Never } \\
(\mathbf{n}=\mathbf{8}, \mathbf{8 7 3})\end{array}$} \\
\hline & $\mathbf{n}$ & $\%$ & $\mathbf{n}$ & $\%$ & $\mathbf{n}$ & $\%$ & $\mathbf{n}$ & $\%$ \\
\hline $12-13$ & 1,001 & 26.7 & 1,674 & 27.5 & 258 & 27.1 & 2,417 & 27.2 \\
\hline$\geq 14$ & 1,935 & 51.7 & 3,004 & 49.4 & 500 & 52.5 & 4,439 & 50.0 \\
\hline Unknown & 84 & 2.2 & 202 & 3.3 & 28 & 2.9 & 258 & 2.9 \\
\hline \multicolumn{9}{|c|}{ Body mass index at first clinic visit $\left(\mathrm{kg} / \mathrm{m}^{2}\right)$} \\
\hline$<25$ & 2,300 & 61.4 & 3,680 & 60.5 & 590 & 62.0 & 5,390 & 60.7 \\
\hline $25-29.9$ & 408 & 10.9 & 613 & 10.1 & 89 & 9.3 & 932 & 10.5 \\
\hline 230.0 & 205 & 5.5 & 268 & 4.4 & 39 & 4.1 & 434 & 4.9 \\
\hline Unknown & 832 & 22.2 & 1,519 & 25.0 & 234 & 24.6 & 2,117 & 23.9 \\
\hline \multicolumn{9}{|l|}{ Oral contraceptive use } \\
\hline Never & 368 & 9.8 & 565 & 9.3 & 132 & 13.9 & 801 & 9.0 \\
\hline Ever & 2,389 & 63.8 & 3,586 & 59.0 & 591 & 62.1 & 5,384 & 60.7 \\
\hline Missing & 988 & 26.4 & 1,929 & 31.7 & 229 & 24.0 & 2,688 & 30.3 \\
\hline \multicolumn{9}{|l|}{ Cause of infertility ${ }^{a}$} \\
\hline Endometriosis & 980 & 26.2 & 1,216 & 20.0 & 268 & 28.1 & 1,928 & 21.7 \\
\hline Anovulation & 1,472 & 39.3 & 1,277 & 21.0 & 401 & 42.1 & 2,348 & 26.5 \\
\hline Tubal disease/pelvic adhesions & 1,227 & 32.8 & 2,259 & 37.2 & 325 & 34.1 & 3,161 & 35.6 \\
\hline Male factor & 816 & 21.8 & 1,402 & 23.1 & 198 & 20.8 & 2,020 & 22.8 \\
\hline Cervical disorder & 327 & 8.7 & 284 & 4.7 & 133 & 14.0 & 478 & 5.4 \\
\hline Uterine disorder & 393 & 10.5 & 660 & 10.9 & 115 & 12.1 & 938 & 10.6 \\
\hline Unexplained & 183 & 4.9 & 175 & 2.9 & 44 & 4.6 & 314 & 3.5 \\
\hline Incomplete workup & 515 & 13.8 & 1,494 & 24.6 & 96 & 10.1 & 1,913 & 21.6 \\
\hline
\end{tabular}

${ }^{a}$ Conditions are not mutually exclusive (i.e., women could be classified as having more than one cause of infertility). 
TABLE 2

Relationship of selected demographic and health characteristics with ovarian cancer among women evaluated for infertility at five US clinics between 1965 and 1988.

\begin{tabular}{|c|c|c|c|c|}
\hline & $\begin{array}{l}\text { No. of } \\
\text { cases }\end{array}$ & $\begin{array}{r}\text { Person- } \\
\text { years }\end{array}$ & $\mathbf{R R}^{a}$ & $95 \% \mathrm{CI}$ \\
\hline \multicolumn{5}{|l|}{ Race } \\
\hline White & 70 & 192,733 & 1.00 & Reference \\
\hline African American & 2 & 11,182 & 0.48 & $(0.12,2.00)$ \\
\hline Other & 3 & 13,562 & 0.61 & $(0.19,1.95)$ \\
\hline Unknown & 10 & 38,970 & & \\
\hline \multicolumn{5}{|c|}{ Age at first clinic visit (y) } \\
\hline$<25$ & 7 & 25,851 & 1.00 & Reference \\
\hline $25-29$ & 33 & 105,470 & 1.07 & $(0.47,2.43)$ \\
\hline $30-34$ & 29 & 88,799 & 1.16 & $(0.49,2.76)$ \\
\hline $35-39$ & 11 & 30,173 & 1.26 & $(0.45,3.47)$ \\
\hline$\geq 40$ & 5 & 6,155 & 2.69 & $(0.76,9.44)$ \\
\hline \multicolumn{5}{|c|}{ Reproductive status at first clinic visit } \\
\hline Nulligravid & 46 & 108,462 & 1.00 & Reference \\
\hline $\begin{array}{l}\text { Ever pregnant at } \\
\text { first clinic visit }\end{array}$ & 39 & 147,986 & 0.61 & $(0.40,0.94)$ \\
\hline \multicolumn{5}{|l|}{$\begin{array}{l}\text { Reproductive status at } \\
\text { follow-up }\end{array}$} \\
\hline Nulligravid & 19 & 34,160 & 1.00 & Reference \\
\hline Ever pregnant & 46 & 183,276 & 0.45 & $(0.26,0.77)$ \\
\hline Missing & 20 & 39,012 & & \\
\hline \multicolumn{5}{|l|}{ Age at first birth (y) } \\
\hline Nulliparous & 29 & 50,814 & 1.00 & Reference \\
\hline$<25$ & 4 & 27,386 & 0.26 & $(0.09,0.75)$ \\
\hline $25-29$ & 10 & 43,742 & 0.40 & $(0.19,0.82)$ \\
\hline 230 & 15 & 65,747 & 0.39 & $(0.21,0.73)$ \\
\hline Missing & 27 & 68,758 & & \\
\hline \multicolumn{5}{|l|}{ Age at menarche (y) } \\
\hline$<12$ & 14 & 50,023 & 1.00 & Reference \\
\hline $12-13$ & 18 & 69,201 & 0.95 & $(0.47,1.90)$ \\
\hline$\geq 14$ & 50 & 129,803 & 1.39 & $(0.77,2.52)$ \\
\hline Missing & 3 & 7,421 & & \\
\hline \multicolumn{5}{|c|}{ Body mass index at first clinic visit $\left(\mathrm{kg} / \mathrm{m}^{2}\right)$} \\
\hline$<25$ & 52 & 156,347 & 1.00 & Reference \\
\hline $25-29.9$ & 15 & 25,892 & 1.81 & $(1.01,3.23)$ \\
\hline 230.0 & 4 & 11,358 & 1.15 & $(0.41,3.20)$ \\
\hline Missing & 14 & 62,850 & & \\
\hline \multicolumn{5}{|l|}{ Oral contraceptive use } \\
\hline Never & 8 & 23,990 & 1.00 & Reference \\
\hline Ever & 54 & 155,924 & 1.10 & $(0.52,2.32)$ \\
\hline
\end{tabular}

Fertil Steril. Author manuscript; available in PMC 2014 December 01. 


\begin{tabular}{lrrrr}
\hline & $\begin{array}{r}\text { No. of } \\
\text { cases }\end{array}$ & $\begin{array}{r}\text { Person- } \\
\text { years }\end{array}$ & RR $^{a}$ & 95\% CI \\
Missing & 23 & 76,534 & & \\
Cause of infertility $b$ & & & & \\
$\quad$ Endometriosis & 22 & 54,553 & 1.14 & $(0.67,1.95)$ \\
Anovulation & 23 & 73,168 & 0.95 & $(0.58,1.54)$ \\
$\quad$ Tubal disease/pelvic & 31 & 86,703 & 1.04 & $(0.66,1.66)$ \\
$\quad$ adhesions & & & & \\
$\quad$ Male factor & 24 & 59,079 & 1.27 & $(0.76,2.13)$ \\
$\quad$ Cervical disorder & 6 & 16,038 & 1.56 & $(0.64,3.77)$ \\
$\quad$ Uterine disorder & 9 & 25,554 & 0.88 & $(0.43,1.80)$ \\
\hline
\end{tabular}

$\mathrm{CI}=$ confidence interval.

${ }^{a}$ Hazard rate ratios (RR) adjusted for study site and year of cohort entry.

${ }^{b}$ Conditions are not mutually exclusive, women could be classified as having more than one cause of infertility; risk estimates are relative to women with no evidence of the condition. 


\section{TABLE 3}

Risk of ovarian cancer with ovulation-inducing medication (clomiphene citrate and gonadotropin) exposure among women evaluated for infertility at five US clinics between 1965 and 1988.

\begin{tabular}{|c|c|c|c|c|}
\hline & $\begin{array}{l}\text { No. of } \\
\text { cases }\end{array}$ & $\begin{array}{r}\text { Person- } \\
\text { years }\end{array}$ & $\mathbf{R R}^{a}$ & $95 \% \mathrm{CI}$ \\
\hline Clomiphene citrate (never) & 48 & 159,762 & 1.00 & Reference \\
\hline Clomiphene citrate (ever) & 37 & 96,686 & 1.34 & $(0.86,2.07)$ \\
\hline \multicolumn{5}{|l|}{ Cumulative dosage (mg) } \\
\hline $1-900$ & 18 & 32,641 & 1.93 & $(1.11,3.33)$ \\
\hline$>900$ & 19 & 64,045 & 1.03 & $(0.60,1.77)$ \\
\hline \multicolumn{5}{|l|}{ No. of cycles } \\
\hline$<6$ & 27 & 63,041 & 1.50 & $(0.93,2.42)$ \\
\hline$\geq 6$ & 10 & 33,645 & 1.04 & $(0.52,2.07)$ \\
\hline \multicolumn{5}{|l|}{ Age at first use (y) } \\
\hline$<30$ & 15 & 44,376 & 1.20 & $(0.67,2.17)$ \\
\hline 230 & 20 & 45,893 & 1.52 & $(0.88,2.61)$ \\
\hline Gonadotropins (never) & 77 & 231,841 & 1.00 & Reference \\
\hline Gonadotropins (ever) & 8 & 24,607 & 1.00 & $(0.48,2.08)$ \\
\hline \multicolumn{5}{|l|}{ Cumulative dosage (ampule) ${ }^{b}$} \\
\hline $1-24$ & 3 & 8,214 & 1.13 & $(0.35,3.62)$ \\
\hline$>24$ & 5 & 16,393 & 0.93 & $(0.37,2.31)$ \\
\hline \multicolumn{5}{|l|}{ No. of cycles } \\
\hline$<6$ & 8 & 20,296 & 1.20 & $(0.57,2.50)$ \\
\hline 76 & 0 & 4,311 & & \\
\hline \multicolumn{5}{|l|}{ Age at first use (y) } \\
\hline$<30$ & 2 & 7,371 & 0.83 & $(0.20,3.42)$ \\
\hline 230 & 6 & 16,889 & 1.09 & $(0.47,2.54)$ \\
\hline \multicolumn{5}{|c|}{ Combination of clomiphene citrate and gonadotropins } \\
\hline Neither & 47 & 155,164 & 1.00 & Reference \\
\hline Clomiphene citrate only & 30 & 76,677 & 1.36 & $(0.85,2.17)$ \\
\hline Gonadotropins only & 1 & 4,598 & 0.75 & $(0.10,5.49)$ \\
\hline $\begin{array}{l}\text { Sequential clomiphene } \\
\text { citrate then } \\
\text { gonadotropins }\end{array}$ & 7 & 20,009 & 1.20 & $(0.54,2.68)$ \\
\hline
\end{tabular}

\footnotetext{
${ }^{a}$ Hazard rate ratio (RR) and $95 \%$ confidence intervals (CI) adjusted for clinic site, calendar year of first infertility evaluation, and gravidity status at study entry (ever pregnant at first clinic visit vs. nulligravid at first clinic visit).

b

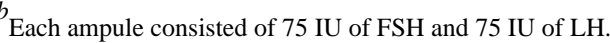




\section{TABLE 4}

Risk of ovarian cancer associated with ever versus never use of clomiphene citrate according to other ovarian cancer risk factors among women evaluated for infertility at five US clinics between 1965 and 1988.

\begin{tabular}{|c|c|c|c|c|}
\hline & $\begin{array}{r}\text { No. of } \\
\text { exposed } \\
\text { cases }\end{array}$ & $\mathbf{R R}^{a}$ & $95 \% \mathrm{CI}$ & $\begin{array}{l}P \text { value for } \\
\text { interaction }\end{array}$ \\
\hline \multicolumn{5}{|l|}{ Age at follow-up (y) } \\
\hline$<50$ & 22 & 1.43 & $(0.80,2.55)$ & .42 \\
\hline $50-59$ & 11 & 1.11 & $(0.51,2.41)$ & \\
\hline 260 & 4 & 1.10 & $(0.30,4.03)$ & \\
\hline \multicolumn{5}{|c|}{ Reproductive status at first clinic visit } \\
\hline Nulligravid & 22 & 1.62 & $(0.90,2.90)$ & .08 \\
\hline $\begin{array}{l}\text { Ever pregnant at first } \\
\text { clinic visit }\end{array}$ & 15 & 1.05 & $(0.54,2.03)$ & \\
\hline \multicolumn{5}{|c|}{ Reproductive status at follow-up } \\
\hline Nulligravid & 13 & 3.63 & $(1.36,9.72)$ & .001 \\
\hline Ever pregnant & 16 & 0.88 & $(0.47,1.63)$ & \\
\hline Unknown & 8 & & & \\
\hline \multicolumn{5}{|l|}{ Causes of infertility $b$} \\
\hline Endometriosis & 10 & 1.01 & $(0.43,2.36)$ & .32 \\
\hline Anovulation & 15 & 1.78 & $(0.73,4.37)$ & .79 \\
\hline $\begin{array}{l}\text { Tubal disease/pelvic } \\
\text { adhesions }\end{array}$ & 11 & 0.98 & $(0.46,2.07)$ & .46 \\
\hline Male factor & 10 & 1.18 & $(0.52,2.68)$ & .41 \\
\hline Cervical disorder & 5 & 3.41 & $(0.38,30.33)$ & .16 \\
\hline Uterine disease & 2 & 0.47 & $(0.10,2.32)$ & .17 \\
\hline
\end{tabular}

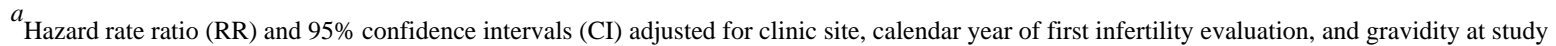
entry.

${ }^{b}$ Conditions are not mutually exclusive (i.e., women could be classified as having more than one cause of infertility).
} 